J Child Adolesc Psychopharmacol Vol. 1(5):361-373 (1991)

ISSN: (print 1044-5463) (online 1557-8992)

doi: 10.1089/cap.1991.1.361

This is a peer reviewed pre-print version of the following article: Beta Blockers in Mental Retardation and

Developmental Disorders, which has been published in final form at:

http://www.liebertpub.com

http://www.liebertpub.com/cap

http://www.liebertonline.com/doi/pdfplus/10.1089/cap.1991.1.361

(C) 1991 Mary Ann Liebert, Inc. Publishers

\title{
Beta Blockers in Mental Retardation and Developmental Disorders
}

\author{
L. Eugene Arnold, M.Ed., M.D. Department of Psychiatry, The Ohio State \\ University, Columbus, Ohio, and Michael G. Aman, Ph.D. The Nisonger Center for \\ Mental Retardation and Developmental Disabilities, The Ohio State University, \\ Columbus, Ohio.
}

\begin{abstract}
$\beta$-Adrenergic blockers appear to be effective in the management of verbal aggression, physical aggression, or self-injurious behavior associated with mental retardation and other developmental disorders. However, methodological limitations of the available studies make it difficult to judge the value of these treatments. Optimal doses for treating patients with mental retardation or developmental disorders appear lower than described in the general psychiatric literature, so low doses of $\beta$-blockers may be preferred in such patients with abnormal brain development. Children and adolescents with mental retardation or developmental disorders appear to respond to particularly low doses (e.g., below propranolol $150 \mathrm{mg}$ daily). Propranolol is recommended for central blockade, and nadolol is recommended for peripheral blockade. Most $\beta$ receptors in the brain (except cerebellum) seem to be $\beta_{1}$ (cardiac type), but it is not clear that central blockade is required for psychotropic effects. Interim suggestions for empirical trials are offered, and rating scales and other measurement approaches are discussed. Since evidence supporting the efficacy of $\beta$-blockers in mental retardation or developmental disorders in children and adolescents is not definitive, the clinician is advised to consider designing an empirical trial for each patient, utilizing pre- and postmedication measures, when conventional treatments have been unsuccessful.
\end{abstract}

\section{Introduction}

Neuroluptic medications comprise the most common form of psychopharmacological management of patients with mental retardation (MR) and other developmental disorders (DD), and are often used for symptomatic control of aggressive and self-injurious behavior (Aman and Singh 1988). Given the potential of these drugs to produce tardive dyskinesia, neuroleptic malignant syndrome, and other side effects, the emerging awareness of the promising clinical utility of the $\beta$-adrenergic blockers is most welcome.

The use of $\beta$-blockers in general psychiatry has been discussed in a recent review by Neppe (1989), and their psychopharmacological use in children and adolescents has been reviewed by Coffey (1990). This article will review (1) the pharmacology of $\beta$-blockers, (2) the use of $\beta$-blockers in general psychiatry, (3) their use in MR/DD, especially in children, (4) suggested guidelines for clinical use in children and adolescents with MR/DD, and (5) the potential role of empirical trials of $\beta$-blockers for children with MR/DD.

\section{Pharmacology}

$\beta$-Adrenergic receptors are found in both neural and nonneural tissues. These receptors can be activated by direct sympathetic nervous transmission and by circulating endocrine catecholamines (norepinephrine, epinephrine, and to a lesser extent dopamine). Both types of 
activation are involved in the general alarm ("fight or flight") reaction to stress, $\beta_{1}$ receptors are found in the heart and brain, and $\beta_{2}$ receptors are mainly vascular, bronchial, and gastrointestinal. In the central nervous system, $\beta$-receptors can be found in the medulla, cerebellum, extrapyramidal system, hypothalamus, limbic forebrain, pineal gland, and neocortex (Conwayetal. 1978, Palacios and Kuhar 1980). Most of these are probably $\beta_{1}$, except that the cerebellum has mainly $\beta_{2}$ receptors.

There are a wide variety of $\beta$-adrenergic blocker agents. The lipid-soluble (lipophilic) drugs cross the blood-brain barrier (propranolol, metroprolol, alprenolol, and pindolol), and the water-soluble (hydrophilic) drugs do not cross as readily (atenolol, nadolol, timolol). Only the lipid-soluble agents are believed to provide significant central blockade. However, it is not at all clear that central blockade is necessary for psychiatric benefit in treating anxiety or aggression (e.g., Alpert et al. 1990, Ratey et al. 1987a,b). The psychotropic effects may be largely or even completely based on peripheral effects. Also, some brain structures, such as the pineal and periventricular nuclei, do not have a blood-brain barrier and are exposed to circulating hydrophilic agents.

The doses needed for central $\beta_{1}$ blockade appear considerably higher than required for peripheral $\beta$-blockade (e.g., Hayes and Schulz 1983).

Propranolol (Inderal or generic) and nadolol (Corgard) block both $\beta_{1}$ and $\beta_{2}$ receptors nonselectively. Atenolol (Tenormin) and metaprolol (Lopressor) are selective $\beta_{1}$ blockers. An ideal central $\beta$-blocker would presumably be both $\beta_{1}$-specific (cardioselective) and lipophilic. Metaprolol (Lopressor) has these features, but has not been well studied for treatment of behavioral problems.

Propranolol is the best studied of the $\beta$-blockers. Approximately two thirds of propranolol is metabolically cleared on first pass through the liver, so that less than $40 \%$ is bioavailable (Wood et al. 1978). Hepatic metabolism produces two active metabolites, hydroxypropranolol and propranolol glycol, the latter having some antiepileptic effect (Fitzgerald and O'Donnell 1971, Shand 1975). The half-life of propranolol is about 4 hours. Therefore, multiple daily doses are needed.

Nadolol and some other $\beta$-blockers have longer half-lives (over $20 \mathrm{~h}$ for nadolol) and require less frequent dosing, at least for cardiovascular indications. The peripherally active hydrophilic $\beta$-blockers are excreted by the kidney without hepatic degradation.

Blockade of $\beta_{1}$ receptors decreases the heart rate; decreased chronotropic and inotropic effects can diminish cardiac output and thereby decrease blood pressure. Blockade of $\beta_{2}$ receptors in the bronchioles increases airway resistance; this can cause bronchospasm in patients with asthma, but is not a problem for nonasthmatic patients (Hayes and Schulz 1987). $\beta$-blockade can also interfere with glycogenolysis during hypoglycemia, necessitating caution in diabetics or other patients prone to hypoglycemia. Central side effects can include toxic psychosis, vivid dreams, insomnia, visual or tactile hallucinations (Conway et al. 1978), lightheadedness, fatigue, and depression (Neppe 1989).

Propranolol can also antagonize central serotonin (5HT) receptors in addition to $\beta$-adrenergic receptors (Weinstock and Weiss 1980), particularly 5HT, receptors (Hoyer 1988). Additionally, propranolol has a membrane-stabilizing effect at high doses (Hayes and Schulz 1983).

Important drug interactions with other lipid-soluble agents (including antidepressants, neuroleptics, benzodiazepines) result from competition for the cytochrome P450 enzyme system. Adding propranolol to any of these psychotropic medications will yield higher circulating levels of 
both drugs, sometimes up to fivefold of the original drug levels (Silber et al. 1981).

\section{General Psychiatric Use of Beta Blockers}

In the late 1960s, propranolol was reported to be beneficial for some anxiety symptoms apparently associated with " $\beta$-adrenergic hypersensitivity" (Granville-Grossman and Turner 1966). Soon, clinicians tried $\beta$-blockers for intractable cases of many disorders, resulting in a considerable list of psychiatric diagnoses for which $\beta$-blockers have been claimed to be helpful.

\section{Anxiety and anxiety disorders}

The effect of $\beta$-blockers on anxiety is perhaps the best studied of their psychiatric uses. Besides uncontrolled open trials, Neppe (1989) counted 15 controlled studies (11 with propranolol) which he felt "established" their efficacy in treating anxiety, at least in regard to "somatic anxiety." Cardiorespiratory anxiety syndromes often seem to benefit from $\beta$-blockers, even when added to partially successful benzodiazepine treatment. In contrast, Neppe (1989), after reviewing the literature, concluded that "psychic anxiety" without significant somatic involvement seems not to be affected by $\beta$-blockers. $\beta$-blockers do not appear to be a treatment of first choice for anxiety disorders, but they can provide a good second line or adjunct (Gualtieri et al. 1983).

Interestingly, the dextroisomer of propranolol, which has little $\beta$-blocking effect but the same membrane-stabilizing activity as the racemic mixture, lacks the antianxiety effect, suggesting that the $\beta$-blockade rather than membrane stabilization is the mechanism relevant to anxiety disorders (Bonn and Turner 1971).

Stress-related reactions are often hyperadrenergic states, $\beta$-blockers have been reported helpful for posttraumatic stress disorder (PTSD) in children (Famularo et al. 1988) as well as for chronic and acute situational stress reactions in adults. Neppe (1989) suggests that much lower doses may be appropriate for treating reactive stress than for treating anxiety disorders, and mentions the efficacy of a p.r.n. dose before stressful situations such as examinations and public speaking.

Panic disorder, which also entails a hyperadrenergic state, might be expected to be a natural candidate for treatment with $\beta$-blockers, so it is surprising that the limited available literature does not support the efficacy of $\beta$-blockers in controlled studies (Neppe 1989). Further, Gorman et al. (1983) reported that $\beta$-adrenergic blockers do not ameliorate lactate-induced panic symptoms, as do antidepressant drugs, which are an established treatment for panic disorder.

\section{Psychoses}

The studies of $\beta$-blockers in schizophrenia and other psychoses have produced mixed results. In general, propranolol is found to be clearly beneficial only when combined with a neuroleptic (e.g., Eccleston et al. 1985, Myers et al. 1981). It is not likely that the direct mechanism of antipsychotic action here is dopamine antagonism, since propranolol does not elevate serum prolactin as do the antidopaminergic neuroleptics (Hansenn et al. 1980). Another possible mechanism could be serotonin antagonism (Lader 1988). The reported efficacy of D-propranolol added to haloperidol (Manchanda and Hirsch 1986) suggests that the mechanism may involve either membrane stabilization or a propranolol-neuroleptic drug interaction that raises neuroleptic blood levels. The entire effect may be explained by the tendency of propranolol to increase circulating levels of neuroleptics, but the combination of a $\beta$-blocker and a moderate dose of a neuroleptic drug sometimes helps when a large dose of a neuroleptic alone did not (Alpert et al. 1990).

When effective for psychosis, $\beta$-blockers must be used in much higher doses than for other 
indications. For example, schizophrenic psychosis has been treated with doses of propranolol from $500 \mathrm{mg}$ (Yorkston et al. 1977) to $1900 \mathrm{mg}$ (Lindstrom and Persson 1980), and manic psychosis has been treated with 2000-3000 mg daily (Emrich et al. 1979). This high-dose requirement suggests that $\beta$-blockers are acting centrally rather than peripherally (see Neppe 1989). Such high doses have been reported to cause serious side effects, including delirium, gastrointestinal symptoms, and paradoxical acute hypertension (Hayes and Schulz 1983). The improvements reported with propranolol generally have been in negative symptoms such as poor socialization, emotional withdrawal, and anergia, as well as on agitation, assaultiveness, and irritability, rather than on hallucinations or delusions.

\section{Aggression}

The "fight" component of the "fight or flight" response may be expressed in the behavioral spectrum of aggression, rage, and hostility, and often is found in such disorders as intermittent explosive disorder, episodic discontrol, or "organic aggressive syndromes." These symptoms have been reported to respond to high doses of $\beta$-blockers in adults (e.g., Yudofsky et al. 1981) and children (e.g., Kuperman and Stewart 1987, Sims and Galvin 1990, Williams et al. 1982). Reviewing the available studies across the age span, Volavka (1988) found an $86 \%$ rate of clinically successful responses, but noted that only one study with 9 patients was controlled.

A mechanism in the central nervous system (CNS) has been proposed that involves the septohippocampal adrenergic system (Neppe 1989). However, the reported success of nadolol, a hydrophilic $\beta$-blocker that does not readily enter the CNS, suggests that the mechanism may be peripheral (Alpert et al. 1990, Ratey et al. 1987).

Neppe (1989) cautions that a high dosage must be administered for several weeks to produce results in treating aggression. The need for a prolonged trial may suggest a mechanism involving changes in receptor sensitivity or regulation.

Despite the equivocal state of the literature, there is enough data to conduct empirical clinical trials in individual cases of aggression unresponsive to more conservative treatments, especially if there is some indicator of brain damage such as acute brain trauma (Elliott 1977) or mental retardation (Kuperman and Stewart 1987).

Self-injurious behavior is a special category of aggression. Luchins and Dojka (1989) report that self-directed aggression and outwardly directed aggression are similarly responsive to $\beta$-blockade.

\section{Other uses of B-blockers}

\section{Substance Withdrawal.}

Withdrawal symptoms from alcohol and many other drugs involve hyperadrenergic states that might be expected to be at least partially alleviated by $\beta$-blockers. The literature now shows only equivocal clinical results (Carlsson 1976, Carlsson and Johansson 1971, see Neppe 1989), but this deserves further exploration in view of the possibility that $\beta$-blockers could provide anxiety relief without dependency, sedation, or abuse potential.

\section{Tremor.}

$\beta$-blockers have been reported to benefit benign essential tremor, lithium-induced tremor, parkinsonian tremor, and tremor associated with anxiety (e.g., Jefferson 1974, Neppe 1989). It is not clear whether the mechanism of action for managing tremor is central or peripheral.

Akathisia. 
Preliminary studies suggest possible benefit for akathisia, but this is not yet firmly established (Adler et al. 1985, 1986, Lipinski et al. 1984, see Neppe 1989). Alpert et al. (1990) report an association between akathisia improvement and aggression score improvement when nadolol was added to a neuroleptic. The benefit of nadolol suggests a peripheral mechanism underlying the effects on both aggression and akathisia, possibly through a reduction in general arousal.

\section{Migraine headache and other neurological conditions}

$\beta$-Blockers are well-established for use in the prevention of migraine, presumably acting through direct vascular effects or relief of anxiety. There are reports of benefit in narcolepsy, phantom limb pain, stuttering, compulsive water drinking, and tardive dyskinesia (Neppe 1989).

\section{Usage in Mental Retardation}

Although older surveys rarely mention the use of $\beta$-blockers in the MR/DD population (Aman and Singh 1988), more recent surveys suggest "pockets" within this clinical population where $\beta$-blockers are used fairly frequently. For example, the Ohio Legal Rights Service found that $13.5 \%$ of residents in one developmental center were prescribed $\beta$-blockers (Johnson and Skinner 1986).

We concluded a systematic search of all clinical reports of the use of $\beta$-blockers for managing behavior disorders in persons with mental retardation or developmental disorders. The search entailed a computer database retrieval of all relevant publications in English, as well as an examination of recent issues of journals specializing in psychopharmacology, mental retardation, or developmental disorders.

Eleven publications were identified that reported empirical data on the effects of $\beta$-blocker in samples which contained a substantial representation (at least $1 / 3$ ) of persons with mental retardation or developmental disorders (see Table 1). Findings are presented for the entire sample and separately for the subjects with MR, when possible. Most of the patients were treated for impulsive physical aggression, verbal aggression, or self-injurious behavior. The mean doses of propranolol ranged from $120 \mathrm{mg} /$ day (Ratey et al. 1986) to $214 \mathrm{mg} /$ day (Ratey et al. 1987a, 1987b). As pointed out by Ratey et al. (1986), this range is markedly lower than doses reported in some studies of nonretarded psychiatric patients, in which large doses of propranolol (> 520 $\mathrm{mg}$ /day) were needed for efficacy (Greendyke et al. 1984, Shepard 1979, Yudofsky et al. 1981).

A high positive response rate was reported, both for the entire group of subjects $(78 \%$ positive) and for patients with MR (81\%). In individuals with MR, therapeutic changes were seen principally in verbal aggression, physical aggression, and self-injurious behavior. The latency of response was reported to vary from a few days ("almost overnight" in Jenkins and Maruta 1987) to up to 6 weeks (Ratey et al. 1987b).

In two studies, nadolol was used successfully in place of propranolol. In one case, substitution was made because of a patient's refusal to take propranolol (Polakoff et al. 1986). In the other study, the reason was the convenience of dosing with the longer half-life of nadolol (Ratey et al. 1987a,b). Since nadolol is thought to have a predominantly peripheral action, some workers have speculated that $\beta$-blockers act by "soothing" and "calming" peripheral arousal mechanisms, at least in some patients with MR (Polakoff et al. 1986, Ratey et al. 1987b).

One report looked at cardiovascular measures as potential predictors of drug response (Kuperman and Stewart 1987). Although the blood pressure changes appeared to be unrelated to behavioral changes, the positive behavioral responders were less likely to show bradycardia with propranolol. 
The strong suggestion of efficacy of the $\beta$-blockers for reducing aggression in patients with mental retardation or developmental disorders must be tempered by several limitations in the data. Foremost, none of these studies employed standard precautions such as contrast groups, placebo, or double-blind controls. Second, the subjects varied markedly in age, psychiatric diagnosis, and intellectual level, both within and across studies. Third, $\beta$-blockers were given in conjunction with other psychotropic drugs, usually neuroleptic drugs, in all of the studies. This is scientifically problematic: since $\beta$-blockers tend to increase the blood levels of neuroleptics, some of the changes observed could have been due to enhanced neuroleptic levels rather than the $\beta$-blocker. (It may be noted that, in the vast majority of cases, the doses of adjunctive neuroleptics were able to be reduced during propranolol treatment.) Fourth, only 4 of the 11 studies employed some objective measures to assess change in aggression, and none used such indices to assess preto postmedication effects for all subjects. This lack of objective measurements undermines confidence in the findings. Finally, it should be noted that most of these were case reports or retrospectively gathered patient data; the well-known tendency to publish successes rather than failures may have biased this early literature. Ruedrich et al. (1990), who independently conducted an appraisal of this literature, also commented on some of these issues.

Despite these major limitations, there is enough evidence to warrant prospective controlled trials of the $\beta$-blockers in the treatment of physical or verbal aggression or self-injurious behavior in patients with mental retardation or developmental disorders. Indeed, this should be a high priority for the field. In view of the reports of efficacy of nadolol, it would also be sensible to conduct trials comparing propranolol and nadolol to determine whether the mechanism is related to a peripheral action, a central action, or a combination. It may be worthwhile to continue to look for predictors of a positive behavorial response. As suggested by Kuperman and Stewart (1987), cardiovascular measures may warrant special attention in this respect.

\section{Recommendations for Clinical Use of $\beta$-Blockers in Children and Adolescents with MR/DD}

Of the 11 reports listed in Table 1 on $\beta$-blockers used in the treatment of patients with mental retardation or developmental disorders, only three studies included préadolescent children and one additional study included 


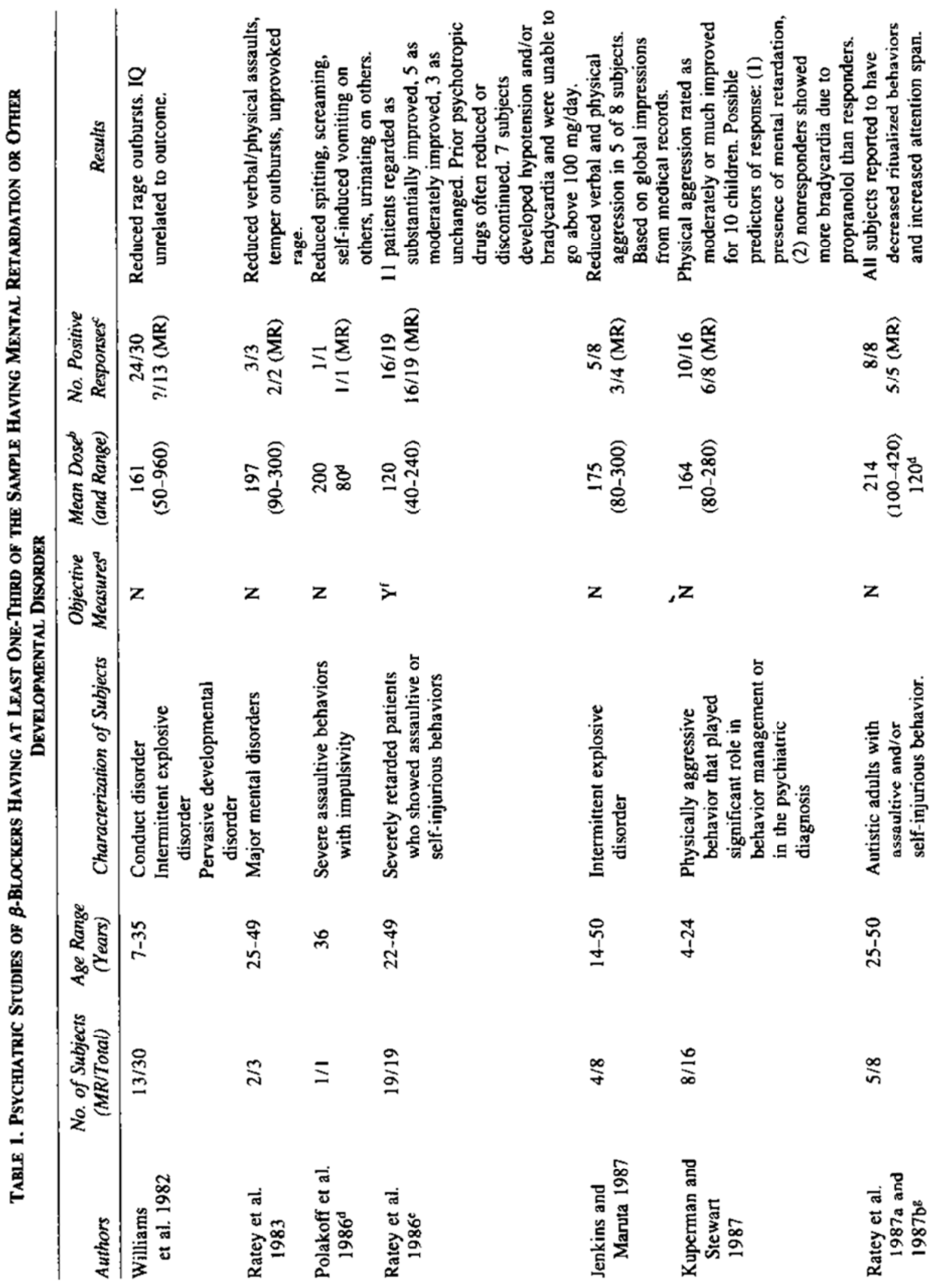



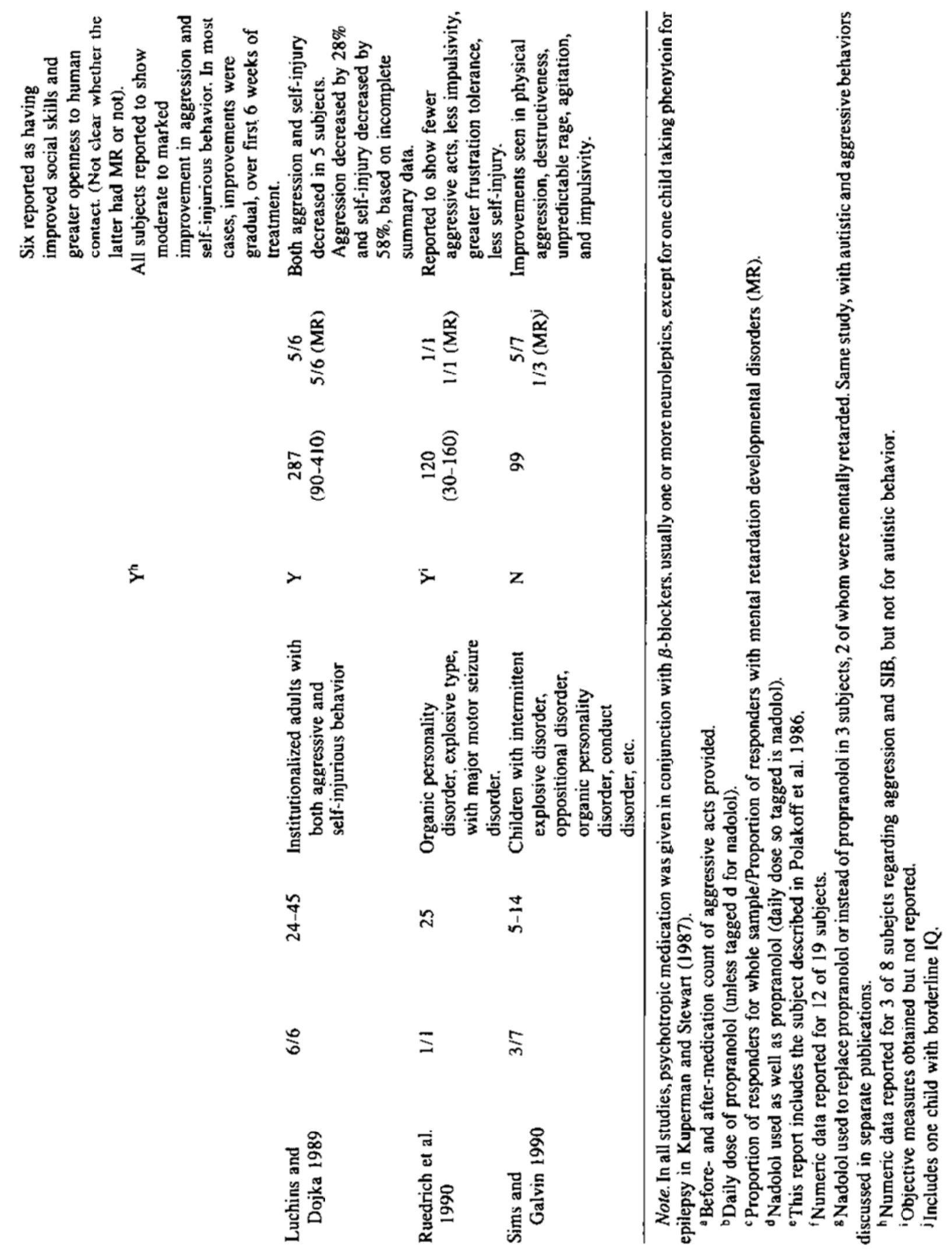
adolescents. These few studies are too limited to draw databased distinctions between (3-blocker treatment of adults and treatment of children and adolescents with mental retardation or developmental disorders. Two tentative observations, about dosage and cardiovascular monitoring, may be ventured.

As noted above, the dosage for patients of all ages with mental retardation or developmental disorders seems less than that recommended for adults with normal IQ. It is not clear whether the organic damage, a difference in brain functioning, the amount of brain substrate, the type of target symptom, the pattern of comorbid disorders or concurrent symptoms, or some other factor is responsible for this apparent IQ-related difference in drug response. Furthermore, the daily doses recommended by Coffey (1990) for normal IQ children (10-120 mg propranolol) and adolescents (20-300 mg propranolol) are also less than for adults with normal IQ, even after correction for body weight. Presumably, children with mental retardation or developmental disorders might be expected to require the lowest doses of all. Table 1 provides a small amount of support for this expectation. The six reports that included no adolescents or children used a mean daily dose of $210 \mathrm{mg}$ propranolol. The four studies that included adolescents or children used a mean dose of 150 $\mathrm{mg}$. The one study that focused on younger children ( $\leq$ age 14) used a mean dose of $99 \mathrm{mg}$ propranolol. It would seem appropriate to try low dosages of $\beta$-blockers in children with $\mathrm{MR} / \mathrm{DD}$ before trying more conventional doses.

A minor adjustment may also be considered in the cardiovascular monitoring of young patients on B-blockers. Although a pulse rate of $50 / \mathrm{min}$ is considered safe for adults, Coffey (1990) recommends keeping pulse rates above $60 / \mathrm{min}$ in children. This undoubtedly includes children with mental retardation or developmental disorders. Blood pressure, on the other hand, is normally lower in children than adults, so blood pressure can probably be safely maintained at a slightly lower level in children.

\section{Practical guidelines}

Since data on the use of $\beta$-blockers in children and adolescents with mental retardation or developmental disorders are rather sketchy, the following clinical suggestions are abstracted from both the child and the general psychiatric literature, and mainly from clinical guidelines offered by Williams et al. (1982), Ayd (1985), Ratey et al. (1986), Kuperman and Stewart (1987), Neppe (1989), and Coffey (1990):

1. By history and physical examination (and laboratory tests as needed), exclude patients with significant cardiorespiratory pathology (asthma, congestive heart failure, angina), insulin-dependent diabetes, severe vascular disease, severe renal disease, and hyperthyroidism. Family medical history of diabetes and mood disorder should be obtained. Informed consent needs to mention the relative novelty of the treatment.

2. A ß-blocking agent may be the treatment of choice for aggression, hostility, or rage associated with concussion or acute encephalitis.

3. An empirically conducted clinical trial can be justified for managing (a) self-directed aggression or outwardly directed violence (Luchins and Dojka 1989), (b) aggressive behavior in a child or adolescent with brain dysfunction, such as mental retardation or developmental disorders (Kuperman and Stewart 1987), and (c) possibly stimulant-resistant cases of attention-deficit hyperactivity disorder with conduct disorder.

4. Except in special cases (such as asthmatic patients), it is advisable to use a noncardioselective agent without intrinsic sympathomimetic activity. At this time, propranolol (Inderal or generic) is the most commonly used centrally active ß-blocker, and nadolol. (Corgard) is the preferred peripherally active agent. 
5. A prospective behavioral monitoring system should be selected before initiation of the drug. Behavioral observations, counts, or ratings should be obtained at baseline and repeated at each dose. Six potentially useful rating scales and other quantification methods are discussed in the final section of this article.

6. Dosage titration: Start with $10-40 \mathrm{mg}$ propranolol daily in divided doses (10 $\mathrm{mg}$ daily for small children). For inpatients, monitor standing blood pressure and heart rate daily. For outpatients, monitoring should be obtained every 7-14 days, or at each dose increase (whichever involves more intensive monitoring). Dosage can be increased every 3 days by $10-30 \mathrm{mg} /$ day for closely monitored inpatients, or every 4-7 days for outpatients.

7. Heart rate needs to be monitored at each medical visit, and may limit dose elevation. Whenever the pulse is below 50 (adults and older adolescents) or 60 (younger adolescents and children), the next dose should be skipped and the daily dosage re-evaluated.

8. Blood pressure also requires close monitoring, and may also limit dosage. Coffey (1990) and Kupperman and Stewart (1987) have recommended holding a dose if the blood pressure drops below 90/60. This is also the recommended threshold for blood pressure in adults (Ayd 1985, Neppe 1990) and undoubtedly applies to adolescents. However, we suspect that small children could safely tolerate a slightly lower pressure.

9. Keep in mind that patients with brain damage, mental retardation, or developmental disorders may be much more sensitive to low doses of psychotropic agents than are patients with normal brain structure or normal IQ. Also, variations in genetic enzyme and hepatic biotransformation rates may cause further deviations from standard dosing regimens.

10. Titrate the dosage upward until the appearance of intolerable side effects (usually cardiovascular signs) or clinical improvement. Although doses of propranolol approaching $1000 \mathrm{mg}$ have been recommended for adults with normal IQ, our literature review (Table 1) suggests a mean and median optimal daily dose about 200 $\mathrm{mg}$ (range $30-420 \mathrm{mg}$ ) in adult patients with mental retardation or developmental disorders, and probably below $150 \mathrm{mg}$ daily in children with MR. Reported daily doses of nadolol, whose half-life is longer and which requires less frequent dosing, are about half the daily doses of propranolol.

11. Hold the maximum tolerated dose for at least 4 weeks before considering a trial of a $\beta$-blocker to be a failure.

12. It is common practice to add a $\beta$-blocker to another psychtropic agent, usually a psychopharma-cological treatment already in progress. The available literature supports that this is more efficacious than using it alone. However, plasma levels of neuroleptics, anticonvulsants, and antidepressants may increase severalfold with addition of propranolol. Special caution should be exercised with thioridazine because of the risk of pigmentary retinopathy.

13. When a $ß$-blocker is discontinued, taper it over a 2 -week period to prevent rebound tachycardia.

14. After a patient has been successfully maintained for a substantial period of time, consideration should be given to cautious gradual "weaning" to see if the patient can maintain the improvement with a lower dose or possibly even discontinuation. If deterioration occurs, the previous effective dose should be resumed.

\section{Empirical Trials of $\beta$-Blockers in Mental Retardation or Developmental Disorders}


The existing research suggests that a definite role has not yet been established for the use of $\beta$-blockers for treating patients of any age who have mental retardation or other developmental disorders. However, there are sufficient suggestions of efficacy to warrant empirical clinical trials in patients with mental retardation or developmental disorders when other treatments (e.g., behavior modification, neuroleptics, lithium carbonate) have been unsuccessful. In this population, $\beta$-blockers appear to be helpful in managing some patients with severe verbal or physical aggressive or self-injurious behavior, and speculatively with severe anxiety or hyperactivity. Empirical trials should be undertaken with a data collection method that enables informed decisions to be made about the usefulness of treatment.

\section{Methods of assessment}

The two principal sources of empirical data when conducting clinical drug trials are target behavior observation and rating scales (see Aman and White 1986).

\section{Target Behavior Observations.}

Direct observation of the behaviors of concern (e.g., aggressive episodes) may entail measures of response duration (as in tantrums), interval recording, frequency counts, or momentary time sampling (Aman and White 1986).

In measuring response duration, every instance of the target behavior is actually timed, usually with a stopwatch. Interval recording involves dividing the observational period into numerous intervals of equal length. The observer's task is to note whether or not each target behavior occurs within each interval over time. This results in an occurrence measure (a percentage of time intervals) for each of the behavioral categories. Interval recording is probably the most frequently used form of direct observation for assessing psychotropic drugs, and has the best-researched methods for determining its reliability (Aman and White 1986). Frequency counts entail the systematic recording of all occurrences of the target behavior over standard units of time. Momentary time sampling (also called point sampling) involves the brief observation of behavior at regular or randomized intervals (e.g., every 20 minutes) and the recording of all observational categories that are occurring at that moment.

Response duration is most suitable for behaviors of relatively long duration, such as on-task behavior and screaming bouts. Frequency counts are most suitable for assessing low-rate discrete behaviors, such as fighting, that may not be detected in short observational sessions (Aman and White 1986). Momentary time sampling can be relatively cost effective and may be preferred when the target behaviors vary widely over the course of the day.

All forms of direct observation entail the formulation of explicit behavioral definitions of what the patient must do (or not do) in order to be scored positive for the behavior. Most developmental centers and group homes have behavioral specialists who assist in collecting such information.

\section{Rating Scales.}

Several well-validated behavior rating scales might be considered. The Social Dysfunction and Aggression Scale (SDAS) is an observer-completed form that includes 9 items concerning outward aggression and 2 items related to inward aggression (Wistedtet al. 1990). The Overt Aggression Scale (OAS) permits each episode of aggressive behavior to be scored on one of four ordinal subscales: (1) verbal aggression, (2) physical aggression toward objects, (3) physical aggression toward self, and (4) physical aggression against 
other people (Yudofsky et al. 1986). The Staff Observation Aggression Scale (SOAS) is an instrument for quantifying specific aggressive acts on three relevant dimensions: (1) method used in committing the aggression, (2) the aim of the aggression, and (3) the consequences of the aggression (Palmstierna and Wistedt 1987). However, all of these instruments (SDAS, OAS, SOAS) were developed for nonretarded clinical populations and, to the best of our knowledge, their applicability in mental retardation and developmental disorders has not been well studied. Also, the SOAS does not have adequate sections to monitor self-injurious behavior.

In a recent exhaustive review of the available instruments for assessing behavior disorders in mental retardation (Aman 1991), the Behavior Problems Inventory (BPI) emerged as one of the more suitable instruments for assessing aggression and self-injury (Rojahn 1989,Rojahnetal. 1989). The BPI comprises 15 self-injurious behavior items, 5 Stereotypie behavior items, and 9 aggressive behavior items. Raters are asked to determine whether a given item applies to a patient and, if so, to rate its frequency on a 6-point scale from 1 (less than monthly) to 6 (more than once per hour).

Another important option is the Aberrant Behavior Checklist (ABC), a general-purpose rating scale that was specifically developed for assessing treatment effects in mentally retarded people (Aman and Singh 1986, Aman et al. 1985a, 1985b). The ABC encompasses 58 items that load onto five subscales: (1) irritability, agitation, crying (15 items); (2) lethargy, social withdrawal (16 items); (3) Stereotypie behavior (7 items); (4) hyperactivity, noncompliance (16 items); (5) inappropriate speech (4 items). This instrument has been shown to be very sensitive to the effects of a variety of psychotropic drugs. Incorporating the ABC in any pharmacological evaluation would be particularly helpful in determining how behaviors other than aggression and self-injury are affected.

Finally, the Self-Injurious Behavior Questionnaire has been released (Gualtieri and Schroeder 1989), but published data on its psychometric properties are not yet available. These and other instruments reviewed in the Aman (1991) monograph will be discussed in a future paper to appear in the Mental Retardation section of this Journal.

In summary, since the evidence supporting the efficacy of ß-blockers in mental retardation or developmental disorders in children and adolescents is not definitive, the clinician is well advised to design an empirical trial for each patient, utilizing pre- and postmedication measures. Many questions remain unanswered, including the possibility of IQ-related differences in drug réponse (e.g., efficacy, dose requirements, or adverse effects) and the possible clinical value of peripherally acting medications. We hope that controlled studies of $\beta$-adrenergic blocking agents in the management of children and adolescents with mental retardation and developmental disorders will be forthcoming soon.

\section{Acknowledgments}

Work on this paper was supported in part by a research project grant from the National Institute of Mental Health (Grant MH 44122) to Dr. M.G. Aman. The authors would like to thank Deb E. McGhee from the Nisonger Center for assistance in locating relevant source materials and technical help on the manuscript.

\section{References}

Adler L. Angrist B, Peselow E, Corwin J, Maslansky R, Rotrosen J: A controlled assessment of propranolol in the treatment of neuroleptic-induced akathisia. Br J Psychiatry 149:42-45, 1986

Adler L, Angrist B, Peselow E, Corwin J, Rotrosen J: Efficacy of propranolol in neuroleptic-induced akathisia. J Clin Psychopharmacol 5:164-166, 1985

Alpert M, Allan ER, Citrome L, Laury G, Sison C, Sudilovsky A: A double-blind, placebo-controlled study of adjunctive nadolol in the management of violent psychiatric patients. Psychopharmacol Bull 26:367-371, 
1990

Aman MG: Assessing psychopathology and behavior problems in persons with mental retardation: A review of available instruments. Rockville (MD), U.S. Department of Health and Human Services, 1991

Aman MG, Singh NN: Patterns of drug use, methodological considerations, measurement techniques, and future trends. In: Psychopharmacology of the Developmental Disabilities. Edited by Aman MG, Singh NN. New York, Springer Verlag, 1988, pp 1-28

Aman MG, Singh NN: Aberrant Behavior Checklist Manual. East Aurora (NY), Slosson Educational Publications, 1986

Aman MG, White AJ: Measures of drug change in mental retardation. In: Advances in Learning and Behavioral Disabilities. Edited by Gadow KD. Greenwich (CT), JAI Press, 1986, pp 157-202

Aman MG, Singh NN, Stewart AW, Field CJ: The Aberrant Behavior Checklist: A behavior rating scale for the assessment of treatment effects. Am J Ment Defic 89:485-491, 1985a

Aman MG, Singh NN, Stewart AW, Field CJ: The Aberrant Behavior Checklist. Psychopharmacol Bull $21: 845-850,1985 b$

Ayd FJ: Propranolol for aggression: Literature review and clinical guidelines. Intl Drug Ther Newsletter 20:9-12, 1985

Bonn J and Turner P: d-Propranolol and anxiety. Lancet 1:1355-1356, 1971

Carlsson C: Propranolol in the treatment of alcoholism: A review. Postgrad Med J 52:166-167, 1976

Carlsson C. Johansson T: The psychological effects of propranolol in the abstinence phase of chronic alcoholics. Br J Psychiatry 119:605-606, 1971

Coffey BJ: Anxiolytics for children and adolescents: Traditional and new drugs. J Child Adolescent Psychopharmacol 1:57-83, 1990

Conway J, Greenwood DT, Middlemiss D: Central nervous actions of beta-adrenoreceptor antagonists. Clin Sei Mol Med 54:119-124

Eccleston D, Fairbairn AF, Hassanyeh F, McClelland HA, Stephens DA: The effect of propranolol and thioridazine on negative symptoms of schizophrenia. Br J Psychiatry 147:623-630, 1985

Elliott FA: Propranolol for the control of belligerent behavior following acute brain damage. Ann Neurol $1: 489-491,1977$

Emrich HM, von Zerssen D, Moller HJ, Kissling W, Cording C, Schietsch JH, Riedel E: Action of propranolol in mania: Comparison of effects of the d- and the 1-stereoisomer. Pharmacopsychiatry Neuropsychopharmacol 12:295-304, 1979

Famularo R. Kinscherff R, Fenton T: Propranolol treatment for childhood posttraumatic stress disorder, acute type. A pilot study. Am J Dis Child 142:1244-1247. 1988

Fitzgerald JD, O'Donnell SR: Pharmacology of 4-hydroxypropranolol, a metabolite of propranolol. Br J Pharmacol 43:222-235, 1971

Gorman JM, Levy GF, Liebowitz MR, McGrath P, Appleby IL, Dillon DJ, Davies SO, Klein DF: Effect of acute beta-adrenergic blockade on lactate-induced panic. Arch Gen Psychiatry 40:1079-1082, 1983

Granville-Grossman KL, Turner P: The effect of propranolol on anxiety. Lancet 1:788-790, 1966

Greendyke RM, Kanter DR: Therapeutic effects of pindolol on behavioral disturbances associated with organic brain disease: A double-blind study. J Clin Psychiatry 47:423-426, 1986

Greendyke R, Schuster D, Wooten J: Propranolol in the treatment of assaultive patients with organic brain disease. J Clin Psychopharmacol 5:282-285, 1984

Gualtieri CT, Golden RN, Fahs JJ: New developments in pédiatrie psychopharmacology. J Dev Behav Pediatr 4:202-209, 1983

Gualtieri CT, Schroeder SR: Pharmacotherapy for self-injurious behavior: Preliminary tests of the D, 
hypothesis. Psychopharmacol Bull 25:364-371, 1989

Hanssen T, Heyden T, Sundberg I, Alfredsson G, Nyback H, Wetterberg L: Propranolol in schizophrenia. Arch Gen Psychiatry 37:685-690, 1980

Hayes PE, Schulz SC: The use of beta-adrenergic blocking agents in anxiety disorders and schizophrenia. Pharmacotherapy 3:101-117, 1983

Hayes PE, Schulz SC: Beta blockers in anxiety disorders. J Affective Disord 13:119-130, 1987

Hoyer D: Functional correlates of serotonin 5-HT, recognition sties. J Recept Res 8:59-81, 1988

Jefferson JW: Beta-adrenergic blocking drugs in psychiatry. Arch Gen Psychiatry 31:681-691, 1974

Jenkins SC, Maruta T: Therapeutic use of propranolol for intermittent explosive disorder. Mayo Clin Proc 62:204-214, 1987

Johnson J, Skinner A: Medication use in developmental centers. In: Apologist. Columbus (OH), Ohio Legal Rights Service, 1986, pp 1-6

Kuperman S, Stewart MA: Use of propranolol to decrease aggressive outbursts in younger patients. Psychosomatics 28:315-319, 1987

Lader M: Beta adrenoceptor antagonists in neuropsychiatry: An update. J Clin Psychiatry 49:213-223, 1988

Lindstrom LH, Persson E: Propranolol in chronic schizophrenia: A controlled study of neuroleptic-treated patients. Br J Psychiatry 137:126-130, 1980

Lipinski JF, Zubenko GS, Cohen BM, Barreira PJ: Propranolol in the treatment of neuroleptic-induced akathisia. Br J Psychiatry 141:412-415, 1984

Luchins DJ, Dojka MS: Lithium and propranolol in aggression and self-injurious behavior in the mentally retarded. Psychopharmacol Bull 25:372-375, 1989

Manchanda R, Hirsch S: Does propranolol have an antipsychotic effect? A placebo-controlled study in acute schizophrenia. Br J Psychiatry 148:701-707, 1986

Myers DH, Campbell PL, Cocks NM: A trial of propranolol in chronic schizophrenia. Br J Psychiatry 139:105-111, 1981

Neppe VM. Innovative Psychopharmacotherapy. New York, Raven Press, 1989

Palacios JR, Kuhar MJ: Beta-adrenergic-receptor localization by light microscopic autoradiography. Science 208:1378-1380, 1980

Palmstiera TB, Wistedt B: Staff observation aggression scale, SOAS: Presentation and evaluation. Acta Psychiatrica Scand 76:657-663, 1987

Polakoff SA, Sorgi PJ, Ratey JJ: The treatment of impulsive and aggressive behavior with nadolol. J Clin Psychopharmacol 6:125-126, 1986

Ratey JJ, Bemporad J, Sorgi P, Polakoff S, Bick P, O'Driscoll G, Mikkelson E: Brief report: Open trial effects of beta blockers on speech and social behaviors in 8 autistic adults. J Autism Devel Disord 17:439-446, 1987a

Ratey JJ, Mikkelsen EJ, Smith GB, Upadhyaya A. Zuckerman HS, Marello D, Sorgi P, Polakoff S, Bemporad $\mathrm{J}$ : Beta blockers in the severely and profoundly mentally retarded. J Clin Psychopharmacol 6:103-107, 1986

Ratey JJ, Mikkelsen E, Sorgi P, Zuckerman S, Polakoff S, Bemporad J. Bick P, Kaddish W: Autism: The treatment of aggressive behaviors. J Clin Psychopharmacol 7:35-41, 1987b

Ratey JJ, Morrill R, Oxenkrug G: Use of propranolol for provoked and unprovoked episodes of rage. Am J Psychiatry 140:1356-1357, 1983

Rojahn J: Behavior Problems Inventory interview form. Columbus (OH), Ohio State University, 1989 (unpublished)

Rojahn J, Polster LM, Mulick JA: Reliability of the Behavior Problems Inventory. J Multihandicapped Person 2:283-293, 1989 
Ruedrich SL, Grush L, Wilson J: Beta adrenergic blocking medications for aggressive or self-injurious mentally retarded persons. Am J Ment Retard 95:110-119, 1990

Shand DG: Drug therapy: Propranolol. N Engl J Med 293:280-284, 1975

Shepard G: High dose propranolol and schizophrenia. Br J Psychiatry 134:470-476, 1979

Sims J, Galvin MR: Pédiatrie psychopharmacologic uses of propranolol. J Child Adol Psychiatric Ment Health Nurs 3:18-24, 1990

Silber B. Mico BA, Ortiz de Montellano PR, Dois DM, Riegelman S: In vivo effects of the cytochrome p-450 suicide substrate 2-isopropyl-4-pentenamide (allylisopropylacetamide) on the disposition and the metabolic pattern of propranolol. J Pharmacol Exp Ther 219:125-133, 1981

Volavka J: Can aggressive behavior in humans be modified by beta blockers? Postgrad Med (Special Number): 163-168, 1988

Weinstock M, Weiss C: Antagonism by propranolol of isolation-induced aggression in mice: Correlation with 5-hydroxytryptamine receptor blockade. Neuropharmacology 19:653-656, 1980

Williams DT, Mehl R, Yudofsky S, Adams D, Roseman B: The effect of propranolol on uncontrolled rage outbursts in children and adolescents with organic brain dysfunction. J Am Acad Child Psychiatry

21:129-135, 1982

Wistedt B, Rasmussen A, Pedersen L, Traskman-Bendz L, Wakelin J, Bech P: The development of an observer-scale for measuring social dysfunction and aggression. Pharmacopsychiatry 23:249-252, 1990

Wood AJJ, Carr K, Vestal RE, Belcher S, Wilkinson GR, Shand DG: Direct measurement of propranolol bioavailability during accumulation to steady state. Br J Clin Pharmacol 6:345-350, 1978

Yorkston NJ, Gurzelier JH, Zaki SA, Hollander D, Pitcher DR, Sergeant HG: Propranolol as an adjunct to the treatment of schizophrenia. Lancet 2:575-578, 1977

Yudofsky SC, Silver JM, Jackson W, Endicott J, Williams D: The Overt Aggression Scale for the objective rating of verbal and physical aggression. Am J Psychiatry 143:35-39, 1986

Yudofsky S. Williams D, Gorman J: Propranolol in the treatment of rage and violent behavior in patients with chronic brain syndromes. Am J Psychiatry 138:218-230, 1981 